\title{
Genetic Evaluation and Correlation Analysis Among Various Quantitative Traits in Maize Single-Cross Hybrids Under Diverse Environments
}

\author{
Fortunate Makore $^{1}$, Cosmos Magorokosho ${ }^{2}$, Shorai Dari ${ }^{1}$, Edmore Gasura ${ }^{1}$, Upenyu Mazarura ${ }^{1}$, \\ Casper N. Kamutando ${ }^{1} \&$ Xavier Mhike ${ }^{3}$ \\ ${ }^{1}$ Department of Plant Production Science and Technologies, Faculty of Agriculture, Environment and Food \\ Systems, University of Zimbabwe, Harare, Zimbabwe \\ ${ }^{2}$ International Maize and Wheat Improvement Center, Harare, Zimbabwe \\ ${ }^{3}$ Research and Development Agriscope Africa Limited, Nairobi, Kenya \\ Correspondence: Shorai Dari, Department of Plant Production Science and Technologies, Faculty of Agriculture, \\ Environment and Food Systems, University of Zimbabwe, P.O. Box MP 167, Mount Pleasant, Harare, \\ Zimbabwe. E-mail: shoraidari@yahoo.co.uk
}

Received: December 12, 2020

Accepted: February 5, $2021 \quad$ Online Published: April 15, 2021

doi:10.5539/jas.v13n5p104

URL: https://doi.org/10.5539/jas.v13n5p104

The Research is financed by Bill \& Melinda Gates Foundation and USAID, and the CGIAR maize research program.

\begin{abstract}
Genetic variation abundance, high genetic advance coupled with high heritability estimates presents the most suitable condition for selection. Ninety-five hybrids generated from elite and new inbred lines crossed using half diallel mating design were evaluated under diverse environments. The objectives were to estimate genetic variances, heritability of traits and genetic advance and to determine correlations of grain yield and its component characters in maize hybrids. Analysis of variance revealed significant differences among genotypes for all traits studied except for ear rots. Estimates of phenotypic coefficient of variation were slightly higher than genotypic coefficient of variation for all traits suggesting low influence of environment in the expression of these traits. High heritability and genetic estimates were recorded for grain yield $(79 \% ; 30.27 \%)$, plant height $(85 \%$; $102.42 \%)$ and ear height $(86 \% ; 117.15 \%)$ whilst high heritability and low genetic advance were observed for anthesis date $(87 \% ; 5.8 \%)$, texture $(75 \% ; 8 \%)$ and ear position $(71 \% ; 0.23 \%)$. Correlation between environments using grain yield data revealed existence of a very strong positive correlation between CIMMYT2 and RARS2 suggesting that the sites have the same discriminating effect. Correlation among traits revealed that grain yield had significant $(\mathrm{P}<0.05)$ positive correlation with plant height and ear height. Similarly, plant height had significant and positive correlation with ear height while ear position was positively correlated to ear height. Path analysis showed that plant height, ears per plant and ear position had positive direct effects on grain, while anthesis date, ear height, ear position, grain moisture content at harvest and texture indirectly influenced grain yield. These characters' contribution to grain yield is important and the strong association with grain yield implied that these can be used as secondary traits to indirectly select for grain yield performance in this set of germplasm across all the environments.
\end{abstract}

Keywords: maize, single-cross hybrids, direct selection, genetic advance, heritability, path analysis

\section{Introduction}

Maize (Zea mays L.) plays a crucial role in food security and livelihoods of people in the sub-Saharan Africa (SSA) (Kassie et al., 2017). Maize yield in SSA average is 2.1 tons per hectare which is much lower compared to world average of 5.6 tons per hectare (FAOSTAT, 2017). Abiotic stresses such as heat, drought and poor soils with low nitrogen hinder maize productivity in the region (Makumbi et al., 2018; Das et al., 2019). In the current study the focus was on estimating genetic parameters of hybrids evaluated under diverse environments. Genetic parameters such as genetic variability and heritability estimates are crucial in improving selection efficiency and 
in determining breeding progress. Several authors have reported existence of genetic variability and high heritability estimates among tested maize genotypes (Meena et al., 2016; Jilo et al., 2018; Bartaula et al., 2019). Heritability is a measure of phenotypic variance attributable to genetic causes with predictive function in plant breeding (Meena et al., 2016). Traits with high heritabilities can be easily fixed with simple selection and breeding efficiency can be enhanced (Bello et al., 2012). Environmental changes and complexity of yield and its components makes it difficult to explore genetic variability in maize. Indirect selection for yield through selecting traits closely related to yield may be the most efficient technique in yield improvement (Musundire et al., 2019). Selection of best genotypes using grain yield alone under stress conditions is not effective but can be improved via improvement of yield component traits such as anthesis date, anthesis silking interval, plant height, ears per plant among others (Mhike et al., 2012).

Correlation coefficients elaborate the degree of trait association among important quantitative traits and inter relationships of characters under study (Kumar \& Babu, 2015; Malik et al., 2005). Several authors reported high positive and significant correlation coefficients of plant height and ear height with grain yield (Raghu et al., 2011; Seshu et al., 2013: Alhussein et al., 2017). Path coefficient analysis reveals whether the association of traits with yield is caused by direct effects or indirect effects. Plant height showed positive indirect effects to ear height (Jakhar et al., 2017). Genetic correlation and path coefficients estimates are both essential in establishing direct, indirect and total causal effects of yield components. Although these techniques have been extensively studied by many authors there is no set rule on how much each yield component contributes to a particular maize plant population (Malik et al., 2005). The purpose of this study was to estimate genetic parameters such as; genetic variation, heritability, expected genetic advance and trait association of quantitative characters for future hybrid selection.

\section{Method}

\subsection{Germplasm and Test Locations}

Six elite CIMMYT maize inbred lines (CMLs) and nine new lines were crossed to generate single-cross hybrids. CML311, CML312, CML393 are subtropical inbred lines and CML539, CML543, CML566 are mid-altitude elite CIMMYT lines. The new lines were developed by line breeding department breeders and their prominent traits are high grain yield and improved heat and drought stress tolerance and are still under testing. Experimental material comprised of 105 single-cross hybrids: $95 \mathrm{~F}_{1}$ hybrids generated from a $15 \times 15$ half-diallel mating design. Ten commercial checks were used in the study as controls. The commercial checks used are hybrids available in the market (CML312/CML444, SC649, PAN7M81, SC653, SC608, SC719, SC633, SC608, SC727, and CZH15429). The trials were conducted in Zimbabwe and Zambia during the 2017/18 and 2018/19 seasons at: CIMMYT Harare (CIMMYT $=$ low N; CIMMYT2 = optimal), Rattray Arnold Research station $($ RARS $=$ low N; RARS2 = optimal), Chiredzi Research station $(\mathrm{CZ}=$ heat stress; CZ2 = drought stress $)$, ART farm $=$ optimal, Mpongwe south $(\mathrm{MS}=$ optimal $)$ and Lusaka west $(\mathrm{LW}=$ low $\mathrm{N})$. Test locations description is shown in Table 1.

Table 1. Test locations description

\begin{tabular}{lllllll}
\hline Site & Environment & Longitude & Latitude & Altitude (masl) & Annual rainfall $(\mathrm{mm})$ & Annual temp Range $\left({ }^{\circ} \mathrm{C}\right)$ \\
\hline ART & Optimal & $31^{\circ} 03^{\prime} \mathrm{E}$ & $17^{\circ} 49^{\prime} \mathrm{S}$ & 1480 & 830 & $13-28.5$ \\
CIMMYT & Managed Low N & $31^{\circ} 2^{\prime} \mathrm{E}$ & $17^{\circ} 5^{\prime} \mathrm{S}$ & 1483 & 1000 & $10-37$ \\
CIMMYT2 & Optimal & $31^{\circ} 2^{\prime} \mathrm{E}$ & $17^{\circ} 5^{\prime} \mathrm{S}$ & 1483 & 1000 & $11-37$ \\
RARS & Managed Low N & $31^{\circ} 14^{\prime} \mathrm{E}$ & $17^{\circ} 14^{\prime} \mathrm{S}$ & 1300 & 918 & $12.8-28.6$ \\
Chiredzi (CZ) & Heat stress & $31^{\circ} 17^{\prime} \mathrm{E}$ & $21^{\circ} 58^{\prime} \mathrm{S}$ & 425 & 450 & $22-31$ \\
Chiredzi (CZ2) & Managed Drought & $31^{\circ} 17^{\prime} \mathrm{E}$ & $21^{\circ} 58^{\prime} \mathrm{S}$ & 425 & 450 & $23-31$ \\
RARS2 & Optimal & $31^{\circ} 14^{\prime} \mathrm{E}$ & $17^{\circ} 14^{\prime} \mathrm{S}$ & 1300 & 918 & $12.8-28.6$ \\
Lusaka West (LW) & Managed Low N & $28^{\circ} 04^{\prime} \mathrm{E}$ & $15^{\circ} 24^{\prime} \mathrm{S}$ & oli1216 & 1000 & $14.2-28.9$ \\
Mpongwe South (MS) & Optimal & $28^{\circ} 03^{\prime} \mathrm{E}$ & $13^{\circ} 32^{\prime} \mathrm{S}$ & 1206 & 1200 & $19.95-25.3$ \\
\hline
\end{tabular}

Note. masl = metres above sea level; MDS = managed drought stress; RARS = Rattray Arnold research station; ART $=$ Agriculture Research Trust.

\subsection{Experimental Design and Crop Management}

Field trials and agronomic management practices were done according to Badu-Apraku et al. (2012). A total of 105 genotypes (i.e., 95 SXs +10 checks) were evaluated and hybrid trials were laid out at each of the 9 sites 
using an alpha (0.1) lattice design (Patterson et al., 1978). At each site, hybrids were replicated twice, and each replicate nested 21 incomplete blocks, with a block size of five. Each hybrid was planted in a one-row plot, $4 \mathrm{~m}$ long, with an inter-row spacing of $0.75 \mathrm{~m}$ and an intra-row spacing of $0.25 \mathrm{~m}$. Two seeds were sown per each planting station, and later thinned to one plant per station at three weeks after crop emergence (WACE), in order to obtain a plant density of approximately 53333 plants $\mathrm{ha}^{-1}$. To eliminate variation due to border effects, commercial maize hybrids of similar vigor were used as borders (Davis et al., 1981). The hybrids were subjected to four different types of management regimes: optimal, managed drought, low nitrogen stress (Low $\mathrm{N}$ ) and managed heat stress conditions.

\subsection{Variables Measured}

Observations were collected on 13 traits using standard procedures followed by CIMMYT (1985). Plant height (PH) was measured as distance between base of a plant and to the auricle of flag leaf, anthesis date (AD) as number of days to $50 \%$ pollen shedding from day of planting; anthesis silking interval (ASI) as the difference between anthesis days and silking days, ear height (EH) as distance between ground level and the base of the primary ear, ears per plant (EPP) as number of ears per plot as a fraction of number of plants/prolificacy, ear position (EPO) as the ratio of ear height to plant height, stem lodging (SL) as a percentage of plant per plot that had their stem broken, root lodging (RL) as a percentage of plant per plot which had their stems inclined by at least 45 degrees, ear rots (ER) as number of rotten cobs per plot, moisture content (MC) as a percentage grain moisture content at harvest, grain yield in tones $\mathrm{ha}^{-1}$ (GYD) as grain mass per plot adjusted to $12.5 \%$ moisture content. Cob husk cover (HC) and grain texture (TEX) were also recorded for the maize hybrids.

\subsection{Statistical Analysis}

Variance components were calculated using DeltaGen software (Jahufer \& Luo, 2018). Genotypic and phenotypic coefficients of variation were calculated as suggested by Singh and Chaudhary (1985):

$$
\begin{aligned}
& \text { Genotypic coefficient of variation }(\mathrm{GCV})=\frac{\sqrt{\sigma^{2} \mathrm{~g}}}{\mathrm{x}} \times 100 \\
& \text { Phenotypic coefficient of variation }(\mathrm{PCV})=\frac{\sqrt{\sigma^{2} \mathrm{p}}}{\mathrm{x}} \times 100
\end{aligned}
$$

GCV and PCV values obtained were categorized as low (0-10\%), moderate (10-20\%) and high (>21\%) according to Siva-Subramanian and Menon (1973).

Broad sense heritability for traits was estimated as the ratio of genotypic variance to phenotypic variance as a percentage (Singh \& Chaudhary, 1985) as follows:

$$
\text { Heritability }(\mathrm{H})=\frac{\sigma^{2} \mathrm{~g}}{\sigma^{2} \mathrm{~g}+\sigma^{2} \mathrm{e}} \times 100
$$

where, $\sigma^{2} \mathrm{~g}$ is genotypic variance, $\sigma^{2} \mathrm{p}$ is phenotypic variance $\sigma^{2} \mathrm{e}$ is environmental variance, $\sigma^{2} \mathrm{p}$ is $\sigma^{2} \mathrm{~g}+\sigma^{2} \mathrm{e}$.

The heritability estimates were classified into 3 groups according to Elrod and Stanfield (1949); low (0-20\%), moderate (20-50\%) and high (> 50).

Genetic advance percentage of mean (GAM) was calculated using the formula suggested by Shuklar et al. (2006):

$$
\text { Genetic advance of mean }(\mathrm{GAM})=\frac{K \sigma^{2} \mathrm{p}}{\mu} \times 100
$$

where, $\mathrm{K}$ is standardised selection differential constant (2.06) at $5 \%$ selection intensity; $\sigma^{2} \mathrm{p}$ as phenotypic variance and $\mu$ is the mean.

Correlations and path analysis were conducted using the package "agricolae" (De Mendiburu, 2009) in R software (R Core Team, 2020). Genotypic and phenotypic correlation coefficients were estimated as suggested by Kwon and Torrie (1964). Direct and indirect effects were estimated using path analysis as suggested by Dewey and Lu (1959) and developed by Wright (1921). Path coefficients were obtained by solving a set of simultaneous equations as follows:

$$
\mathrm{r}_{\mathrm{ny}}=\mathrm{P}_{\mathrm{ny}}+\mathrm{r}_{\mathrm{n} 2} \mathrm{P}_{2 \mathrm{y}}+\mathrm{r}_{\mathrm{n} 3} \mathrm{P}_{3 \mathrm{y}}
$$

where, $r_{n y}$ is the correlation between one component and yield; $P_{n y}$ is path coefficient between that character and yield; $r_{n 2}$ represents correlation between that character and each of the other components in turn.

Path coefficients values were categorized the coefficient values according to Lenka and Mishra (1973) as: negligible (0.00-0.09), low (0.10-0.19), moderate (0.20-0.29) and high $(0.30-0.99)$. 


\section{Results}

\subsection{Variations}

The traits analyzed in this study include: grain yield (GYD), anthesis date (AD), ear height (EH), plant height $(\mathrm{PH})$, stem lodging $(\mathrm{SL})$, root lodging $(\mathrm{RL})$, husk cover $(\mathrm{HC})$, moisture content $(\mathrm{MC})$, anthesis silking interval (ASI), ear position (EPO), texture (TEX) and ear per plant (EPP) were significant at $(\mathrm{P}<0.05)$ except for ear rots (ER). The coefficients of variation (CV) for most traits were low ranging from 6.21 to 28.2 except for stem lodging, husk cover and ear rots where the CVs were high; 187.9, 148.3 and 150.1 respectively. Grain yield ranged from 0.13 to 15 tons per hectare, plant height from $110 \mathrm{~cm}$ to $360 \mathrm{~cm}$, anthesis silking interval from- 4.5 to 8.5 days. Phenotypic and genotypic coefficients of variation for most traits were very low except for ear rots (29.95; 51.42), stem lodging (45.5; 68.4), root lodging $(45.91 ; 72.71)$, husk cover $(47.46 ; 61.5)$ and anthesis silking interval $(28.73 ; 37.07)$. Phenotypic coefficients of variation (PCV) estimates were greater than genotypic coefficient of variation (GCV) for all traits studied.

\subsection{Heritability and Genetic Advance Estimates}

Heritability ranged from $20 \%$ to $87 \%$ with higher estimates recorded for plant height (85\%), anthesis date (87\%), ear height $(86 \%)$, grain yield $(79 \%)$, texture $(75 \%)$ and ear position $(71 \%)$ and anthesis silking interval $(55 \%)$. Moderate estimates were observed for husk cover (49\%), stem logging (36\%), root logging (28\%), ears per plant $(29 \%)$ and moisture content at harvest $(30 \%)$ whilst for ear rot heritability was the lowest $(20 \%)$. Genetic advance estimates as a percentage of mean ranged from 0.23 to 401.48. High genetic advance as mean percentage estimates (GAM) were recorded for traits such as plant height, ear height, root lodging, stem lodging, grain yield, anthesis silking interval, husk cover and ear rot. Moderate GAM estimate was observed for moisture content at harvest and low estimates were recorded for anthesis date, ear position, grain texture and ears per plant.

Table 2. Summary statistics for grain yield and its component characters measured in 105 maize hybrids

\begin{tabular}{lllllllllll}
\hline Trait & Mean & Min & Max & P-Value & CV & VG & GCV (\%) & PCV (\%) & H (\%) & GAM (\%) \\
\hline Grain yield & $5.23 \mathrm{t} / \mathrm{ha}$ & $0.13 \mathrm{t} / \mathrm{ha}$ & $15.3 \mathrm{t} / \mathrm{ha}$ & $* * *$ & 28.2 & 0.67 & 15.61 & 16.76 & 79 & 30.27 \\
Anthesis Date & $74.88 \mathrm{day}$ & $56 \mathrm{day}$ & $98.5 \mathrm{day}$ & $* * *$ & 6.21 & 1.89 & 1.84 & 1.94 & 87 & 5.80 \\
ASI & $1.38 \mathrm{day}$ & $-4.5 \mathrm{day}$ & $8.5 \mathrm{day}$ & $* * *$ & 8.41 & 0.16 & 28.73 & 37.07 & 55 & 39.14 \\
Plant height & $228.01 \mathrm{~cm}$ & $110 \mathrm{~cm}$ & $360 \mathrm{~cm}$ & $* * *$ & 7.15 & 99.13 & 4.37 & 4.67 & 85 & 102.41 \\
Ear height & $109.98 \mathrm{~cm}$ & $37 \mathrm{~cm}$ & $163.2 \mathrm{~cm}$ & $* * *$ & 10.59 & 55.12 & 6.75 & 7.19 & 86 & 117.15 \\
Ear position & 0.48 & 0.25 & 0.72 & $* * *$ & 9.03 & 0 & 4.16 & 4.85 & 71 & 0.23 \\
Root lodging & $2.92 \%$ & $0 \%$ & $63.75 \%$ & $*$ & 22.93 & 1.8 & 45.91 & 72.71 & 28 & 318.33 \\
Stem lodging & $4.17 \%$ & $0 \%$ & $77.47 \%$ & $* *$ & 187.9 & 3.59 & 45.5 & 68.4 & 36 & 401.48 \\
Ears per plant & 0.86 & 0 & 1.55 & $*$ & 16.58 & 0 & 4.12 & 6.54 & 29 & 0.76 \\
Husk cover & $4.73 \%$ & $0 \%$ & $65 \%$ & $* * *$ & 148.3 & 5.04 & 47.46 & 61.5 & 49 & 368.5 \\
Ear rots & $5.78 \%$ & $0 \%$ & $98.75 \%$ & $\mathrm{~ns}$ & 150.1 & 3 & 29.95 & 51.42 & 20 & 314.91 \\
Texture & 2.76 & 1.5 & 4.5 & $* * *$ & 17.28 & 0.1 & 11.29 & 11.85 & 75 & 8.00 \\
Moisture & $13.05 \%$ & $3.35 \%$ & $38.6 \%$ & $*$ & 20.28 & 0.26 & 3.9 & 6.18 & 30 & 10.26
\end{tabular}

Note. $\mathrm{CV}=$ coefficient of variation; $\mathrm{GCV}=$ genotypic coefficients of variation; $\mathrm{PCV}=$ phenotypic coefficients of variation; $\mathrm{VG}=$ genotypic variance; $\mathrm{H}=$ heritability; $\mathrm{GAM}=$ genetic advance estimates as a percentage of mean; $*, * *, * * *$ significant at $0.05,0.01$ and 0.001 , respectively.

\subsection{Environmental Correlations}

Phenotypic and genotypic environmental correlations of nine sites for grain yield are shown in Table 3 . Significant positive correlations were observed between some of the environments. Highest positive phenotypic correlations for grain yield were observed between CZ and CIMMYT2 (0.61) and the lowest correlations for grain yield were recorded between LW and ART (0.14). Highest positive genotypic correlation was observed between RARS2 and CIMMYT2 (0.86) followed by RARS2 and CZ2 (0.81) whilst the lowest correlation was between CIMMYT and CZ (0.33). 
Table 3. Environmental correlations using grain yield ( $t / h a)$ data for 105 maize hybrids

\begin{tabular}{|c|c|c|c|c|c|c|c|c|c|}
\hline Env & & $\mathrm{CZ2}$ & CIMMYT & RARS & $\mathbf{L W}$ & ART & CIMMYT2 & RARS2 & MS \\
\hline \multirow{2}{*}{$\mathrm{CZ}$} & $\mathrm{P}$ & $0.44 * *$ & 0.17 & $0.29 * * *$ & 0.18 & $0.22 * *$ & $0.61 * *$ & $0.50 * * *$ & $0.54 * *$ \\
\hline & G & 0.65 & 0.33 & 0.43 & 0.40 & 0.49 & $0.85 * * *$ & 0.66 & $0.72 * * *$ \\
\hline \multirow{2}{*}{$\mathrm{CZ2}$} & $\mathrm{P}$ & & 0.17 & $0.43^{*}$ & $0.22 * * *$ & 0.29 & $0.50 * *$ & $0.57 * *$ & $0.51 * *$ \\
\hline & $\mathrm{G}$ & & 0.36 & $0.70 * * *$ & 0.53 & $0.70 * *$ & $0.75^{* *}$ & $0.81 * *$ & $0.72 * *$ \\
\hline \multirow{2}{*}{ CIMMYT } & $\mathrm{P}$ & & & $0.34 * * *$ & 0.15 & $0.21^{*}$ & $0.20 * * *$ & $0.33 * *$ & $0.31^{* *}$ \\
\hline & $\mathrm{G}$ & & & $0.71 * *$ & 0.46 & 0.66 & 0.39 & 0.60 & 0.57 \\
\hline \multirow{2}{*}{ RARS } & $\mathrm{P}$ & & & & $0.26^{* *}$ & 0.19 & $0.29^{*}$ & $0.40 * * *$ & $0.42 * * *$ \\
\hline & G & & & & 0.65 & 0.47 & 0.45 & 0.57 & 0.61 \\
\hline \multirow{2}{*}{$\mathbf{L W}$} & $\mathrm{P}$ & & & & & 0.14 & $0.32^{* *}$ & 0.22 & $0.29^{* *}$ \\
\hline & $\mathrm{G}$ & & & & & 0.51 & $0.72 * * *$ & 0.46 & 0.61 \\
\hline \multirow{2}{*}{ ART } & $\mathrm{P}$ & & & & & & $0.33^{* *}$ & 0.34 & $0.23^{*}$ \\
\hline & G & & & & & & 0.74 & $0.74 *$ & 0.50 \\
\hline \multirow{2}{*}{ CIMMYT2 } & $\mathrm{P}$ & & & & & & & 0.65 & $0.48^{* *}$ \\
\hline & $\mathrm{G}$ & & & & & & & $0.86^{* *}$ & 0.63 \\
\hline \multirow{2}{*}{ RARS 2} & $\mathrm{P}$ & & & & & & & & $0.59^{* * *}$ \\
\hline & G & & & & & & & & $0.75^{* *}$ \\
\hline
\end{tabular}

Note. ${ }^{*}, * *, * * *$ significant at $0.05,0.01$ and 0.001 respectively; $\mathrm{P}=$ phenotypic correlation; $\mathrm{G}=$ genotypic correlation; CIMMYT Harare (CIMMYT $=$ low N; CIMMYT2 = optimal), Rattray Arnold Research station $($ RARS $=$ low N; RARS2 $=$ optimal $)$, Chiredzi Research station $(\mathrm{CZ}=$ heat stress; $\mathrm{CZ2}=$ drought stress $)$, ART farm $=$ optimal, Mpongwe south $(\mathrm{MS}=$ optimal $)$ and Lusaka west $(\mathrm{LW}=$ low $\mathrm{N})$.

\subsection{Trait Correlations}

Correlation analysis was done for different management levels and results had similar trends, hence the use of a combined analysis (Data not shown). Significant positive and negative correlations between grain yield and agronomic traits were recorded (Table 4). Grain yield was significantly and positively correlated to anthesis days, plant height, ear height, ear position, ears per plant, texture, moisture content and was negatively correlated to anthesis silking interval and ear rots. Anthesis silking interval was negatively correlated to plant height, ear height, ear position, ears per plant and moisture content. Anthesis date was positively correlated to plant height, ear height, ear position, root lodging, texture and moisture content and negatively correlated to anthesis silking interval.

Table 4. Correlation coefficients of grain yield and its component traits for 105 single cross maize hybrids

\begin{tabular}{|c|c|c|c|c|c|c|c|c|c|c|c|c|}
\hline & AD & ASI & PH & EH & EPO & RL & SL & EPP & HC & ER & TEX & MC \\
\hline GYG & $0.50^{* * *}$ & $-0.69^{*}$ & $0.82 * *$ & $0.84 * * *$ & $0.57 * * *$ & 0.13 & 0.04 & 0.31 & -0.03 & $-0.24 * * *$ & $0.21 * * *$ & $0.54 *$ \\
\hline AD & & $-0.33 * * *$ & $0.46^{*}$ & $0.55 * *$ & $0.44 * *$ & $0.19^{*}$ & 0.19 & 0.04 & -0.17 & -0.02 & $0.24 * *$ & $0.44 * *$ \\
\hline ASI & & & $-0.64 * *$ & $-0.60 * *$ & $-0.28^{*}$ & -0.11 & -0.02 & $-0.25 * *$ & -0.12 & 0.09 & -0.19 & $-0.27 * *$ \\
\hline PH & & & & $0.88 * * *$ & $0.43 * *$ & 0.06 & -0.05 & $0.33^{* *}$ & 0.11 & -0.07 & $0.23 *$ & $0.45^{* * * *}$ \\
\hline EH & & & & & $0.80 * * *$ & 0.11 & 0.04 & $0.24 * *$ & -0.01 & -0.15 & 0.26 & 0.48 \\
\hline EPO & & & & & & 0.09 & 0.10 & 0.01 & -0.15 & $-0.24 * *$ & 0.19 & $0.35 * *$ \\
\hline RL & & & & & & & $0.45^{* * *}$ & 0.02 & -0.16 & -0.04 & -0.01 & 0.01 \\
\hline SL & & & & & & & & -0.06 & -0.26 & -0.03 & $-0.26^{* *}$ & 0.11 \\
\hline EPP & & & & & & & & & 0.12 & $0.28 * * *$ & 0.10 & 0.15 \\
\hline $\mathrm{HC}$ & & & & & & & & & & 0.20 & -0.03 & $-0.23 *$ \\
\hline ER & & & & & & & & & & & 0.17 & $-0.29 * *$ \\
\hline TEX & & & & & & & & & & & & -0.12 \\
\hline
\end{tabular}

Note. ${ }^{*}, * *, * * *$ significant at $0.05,0.01$ and 0.001 , respectively; grain yield (GYD), anthesis date (AD), ear height (EH), plant height (PH), stem lodging (SL), root lodging (RL), husk cover (HC), moisture content (MC), anthesis silking interval (ASI), ear position (EPO), texture (TEX), and ear per plant (EPP). 


\subsection{Path Coefficient Analysis}

We further partitioned correlations coefficients of secondary traits on grain yield into direct and indirect effects using the path coefficient analysis. We categorized the coefficient values according to Lenka and Mishra (1973) as: negligible 0.00-0.09; low 0.10-0.19; moderate 0.20-0.29 and high 0.30-0.99. Path analysis results from different management levels had similar trends (Data not shown). Correlations combined analysis was done and direct effects of anthesis date, root lodging, stem lodging, husk cover and texture were negligible (Table 5). Plant height, ear position, ear per plant and moisture content had positive direct effects on grain yield. Anthesis silking interval, ear height and ear rots had negative direct effects on grain yield. However, plant height and ear height had indirect positive effects on anthesis silking interval. Anthesis date, ear height, ear position, ears per plant, texture and moisture content had positive indirect effects on plant height whilst anthesis silking interval had negative indirect effects on plant height. Anthesis date, plant height, ear height and moisture content had positive indirect effects on ear position. Plant height and ear position had negative indirect effects on ear height and anthesis silking interval had positive indirect effect on ear height.

Table 5. Path coefficient analysis indicating direct and indirect effects of component characters on grain yield for 105 maize genotypes

\begin{tabular}{|c|c|c|c|c|c|c|c|c|c|c|c|c|c|}
\hline Trait & AD & ASI & PH & EH & EPO & RL & SL & EPP & $\mathrm{HC}$ & ER & TEX & MC & Total effects \\
\hline AD & $0.05^{* *}$ & 0.08 & 0.25 & -0.09 & 0.13 & 0.01 & 0.00 & 0.00 & 0.00 & 0.00 & 0.01 & 0.05 & $0.50 * * *$ \\
\hline ASI & -0.02 & $-0.25^{* *}$ & -0.35 & 0.10 & -0.08 & 0.00 & 0.00 & -0.03 & 0.00 & -0.01 & -0.01 & -0.03 & $-0.69 * * *$ \\
\hline PH & 0.02 & 0.16 & $0.54 * *$ & -0.14 & 0.12 & 0.00 & 0.00 & 0.04 & 0.00 & 0.01 & 0.01 & 0.06 & $0.82 * * *$ \\
\hline EH & 0.03 & 0.15 & 0.48 & $-0.16^{* *}$ & 0.23 & 0.00 & 0.00 & 0.03 & 0.00 & 0.02 & 0.01 & 0.06 & $0.84 *$ \\
\hline EPO & 0.02 & 0.07 & 0.23 & -0.13 & $0.29 * *$ & 0.00 & 0.00 & 0.00 & 0.00 & 0.03 & 0.01 & 0.04 & $0.57 * * *$ \\
\hline RL & 0.01 & 0.03 & 0.04 & -0.02 & 0.02 & $0.04 * *$ & 0.00 & 0.00 & 0.00 & 0.01 & 0.00 & 0.00 & $0.13^{* * *}$ \\
\hline SL & 0.01 & 0.00 & -0.03 & -0.01 & 0.03 & 0.02 & $0.01 * *$ & -0.01 & 0.01 & 0.00 & -0.01 & 0.01 & 0.04 \\
\hline EPP & 0.00 & 0.06 & 0.18 & -0.04 & 0.00 & 0.00 & 0.00 & $0.12 * *$ & 0.00 & -0.04 & 0.00 & 0.02 & $0.31 * * *$ \\
\hline $\mathrm{HC}$ & -0.01 & 0.03 & 0.06 & 0.00 & -0.04 & -0.01 & 0.00 & 0.01 & $-0.02 *$ & -0.03 & 0.00 & -0.03 & $-0.03 *$ \\
\hline $\mathbf{E R}$ & 0.00 & -0.02 & -0.04 & 0.02 & -0.07 & 0.00 & 0.00 & 0.03 & 0.00 & $-0.13 *$ & 0.01 & -0.04 & $-0.24 * * *$ \\
\hline TEX & 0.01 & 0.05 & 0.12 & -0.04 & 0.05 & 0.00 & 0.00 & 0.01 & 0.00 & -0.02 & $0.04 *$ & -0.01 & $0.21 * * *$ \\
\hline MC & 0.02 & 0.07 & 0.24 & -0.08 & 0.10 & 0.00 & 0.00 & 0.02 & 0.00 & 0.04 & -0.01 & $0.12 *$ & $0.54 * * *$ \\
\hline
\end{tabular}

RE 0.18

Note. *, **, *** significant at $0.05,0.01$ and 0.001 , respectively; grain yield (GYD), anthesis date (AD), ear height (EH), plant height (PH), stem lodging (SL), root lodging (RL), husk cover (HC), moisture content (MC), anthesis silking interval (ASI), ear position (EPO), texture (TEX) and ear per plant (EPP).

\section{Discussion}

The analysis of variance for 105 genotypes exhibited significant variability among most of the characters under study except for ear rots which was not significant. The variability can be attributed to diverse source of germplasm coming from new lines and the CIMMYT elite lines crossed to form the single cross hybrids. Phenotypic and genotypic coefficients of variation estimates are very crucial in predicting selection efficiency. The difference between GCV and PCV indicates the environmental influence. In this study the PCVs were slightly higher than GCVs suggesting least environmental influence on characters. Similar results had been reported by Meena et al. (2016) and Alhussein et al. (2017). In contrast Ogunniyan and Olakojo (2015) reported higher GCVs compared to PCVs for traits such as plant height, ear height, number of leaf per plant, ear weight, grain weight, number of ears and leaf area and zero environmental influence for traits such as days to silking, days to anthesis and anthesis silking interval. Ayodele et al. (2020) also reported higher GCVs compared to PCVs suggesting low environmental influence on the expression of characters studied. Higher percentage of GCV provides ample scope for selection and in the current study traits such as grain yield, anthesis silking interval, root lodging, stem lodging, husk cover, ear rots and texture had higher GCV \% estimates.

Heritability is the percentage of genotypic variance over phenotypic variance and is a predictor of the reliability of phenotypic value of quantitative characters. Higher heritability estimates were observed for the following traits: plant height, anthesis date, ear height, grain yield, ear position and texture. Therefore, these characters can be used for selection because variation for traits was under genetic control and traits were less influenced by environment. High heritability values for these traits also imply that traits can be easily passed on to the next 
generation enhancing selection efficiency in maize breeding programs. Jilo et al. (2018) also recorded high heritability estimates for grain yield and plant height. Bartaula et al. (2019) recorded high estimates for plant height at harvest (0.99) and ear height (0.99). In contrast, Alhussein and Idris (2017) recorded very low heritability estimates for grain yield, ear height and plant height. The traits that exhibited moderate heritability were anthesis silking interval, root logging, stem logging, moisture, ears per plant and husk cover may respond positively to phenotypic selection and progress can be made when improving them. Similar results have been recorded for the trait ears per plant by Atta (2016).

Genetic advance as a percentage of mean indicates mode of gene action in the expression of a trait (Meena, 2016) and reveals the degree of gain of a particular trait under selection pressure. The expected genetic advance was low for anthesis date, ear position, ears per plant moisture content and texture. In this study, traits with both high heritability and genetic advance estimates were plant height, ear height and grain yield. These traits can be used for selection because high estimates of heritability coupled with high genetic advance offers the most suitable condition for selection as it indicates the presence of additive genes and are usually more helpful than heritability alone in predicting the resultant effect for selecting the best genotypes (Johnson et al. 1955).

Significant genotypic and phenotypic environmental correlations between a few sites were observed using grain yield data. Strong environmental correlations were recorded between CZ and CIMMYT2 (0.85), CZ2 and RARS2 (0.81), however these environments are known to be different in terms of annual temperature, rainfall and altitude. CIMMYT2 and RARS2 (0.86) also had a very strong environmental correlation, suggesting that only one of the sites could be used for trial evaluation since they have the same discriminating effect.

The complexity of inheritance of traits in maize demands simultaneous selection of grain yield along with other closely related traits to effectively identify best genotypes (Atta, 2016). In this study Pearson's correlation coefficients and path coefficients values were used to establish relationships among grain yield and its components. Grain yield was strongly correlated to plant height and ear height. Plant height was strongly correlated to ear height while ear positon was strongly associated with ear height. Atta (2016) reported high positive and significant genetic correlations among grain yield and its several component traits under low nitrogen conditions. Similar results have been reported by Alhussein (2017). Secondary traits with positive correlations can be indirectly selected for each other and this ensures parallel improvement of these traits. Significant and positive correlation between two characters suggests that these characters can be improved simultaneously in a selection program. Negative correlation observed between traits indicates inverse relationships e.g. grain yield and anthesis silking interval (-0.69): as you increase ASI grain yield decreases.

Direct and indirect association depicts the importance of characters to the final product and in this case grain yield was used as a dependent character to calculate path coefficients at phenotypic level. The independent characters were plant height, ear height, anthesis date, ear position, anthesis silking interval, husk cover, root logging, stem logging, moisture at harvest, ear per plant, ear rots and texture. Path coefficients enable the breeder to concentrate on the variable with high direct effect on grain yield (Kumar \& Babu, 2015). The study revealed that plant height had the maximum positive direct effect on grain yield (0.54), whilst ear position and ears per plant had high and moderate direct effects on grain yield, therefore may be considered together with plant height as selection criteria for grain yield in maize breeding programs. This means that these traits should be seriously considered when selecting high yielding genotypes. Plant height also revealed positive indirect effects via anthesis date, ear height, ear position, grain moisture content at harvest and texture. These traits have direct effects on grain yield and can be used to select for increased grain yield. Wuhaib et al. (2018) reported that ear height, plant height, number of ears and $50 \%$ days to silking had positive direct effect on grain yield. Thus by selecting plant height these traits will also be selected for. Ear height and anthesis silking interval had negative direct effect on grain yield and this means these traits need to be improved before using them as selection criterion.

There was environmental influence on character expression as shown by higher PCV than GCV. High genetic and phenotypic variance, heritability and genetic advance estimates were recorded for plant height, ear height and grain yield. Implication for breeding is that progress can be made through selection for these traits in this set of germplasm. The study was able to reveal trait association of this particular set of hybrids under diverse growing conditions. Grain yield had strong positive correlations with plant height and ear height under diverse environments. Plant height, ears per plant and ear position had positive direct effects on grain, whilst other characters such as anthesis date, ear height, ear position, grain moisture content at harvest and texture indirectly influenced grain yield. These characters' contribution to grain yield is important and the strong association with grain yield implied that these can be used as secondary traits to indirectly select for grain yield performance in this set of germplasm across all the environments. 


\section{Acknowledgements}

This study was funded by the Stress Tolerant Maize for Africa (STMA, Grant no. OPP1134248), project funded by the Bill \& Melinda Gates Foundation and USAID, and the CGIAR maize research program. The authors thank Kelvin Simpasa, Alexander T. Chikoshana, Stanley Gokoma, Irene Viola, Toverengwa Chitana and Semai Viola for data collection at the various experimental sites.

\section{References}

Alhussein, M. B., \& Idris, A. E. (2017). Correlation and path analysis of grain yield components in some Maize (Zea mays L.) genotypes. International Journal of Advanced Research and Publications, 1, 79-82.

Atta, M. M. M. (2016). Genetic correlations and heritability in maize under Low-N and heat stress conditions. Egyptian Journal of Plant Breeding, 20, 241-260. https://doi.org/10.12816/0031701

Ayodele, I. S., Omolaran, B., Aremu, C., \& Abolusoro, S. (2020). Estimation of genetic variation, heritability and genetic advance for yield and agronomic traits correlation of some low nitrogen tolerance maize (Zea mays) varieties in the tropics. Research on Crops, 21, 595-603. https://doi.org/10.31830/2348-7542.2020.093

Badu-Apraku, B., Fakorede, M. A. B., Menkir, A., \& Sanago, D. (2012). Conduct and Management of field trials (p. 59). IITA, Ibadan, Nigeria.

Bartaula, S., Panthi, U., Timilsena, K., Acharya, S. S., \& Shrestha, J. (2019). Variability, heritability and genetic advance of maize (Zea mays L.) genotypes. Research in Agriculture Livestock and Fisheries, 6, 163-169. https://doi.org/10.3329/ralf.v6i2.42962

Bello, O. B., Ige, S. A., Azeez, M. A., Afolabi, M. S., Abdulmaliq, S. Y., \& Mahamood, J. (2012). Heritability and genetic advance for grain yield and its component characters in maize (Zea mays L.). International Journal of Plant Research, 2(5), 138-145, https://doi.org/10.5923/j.plant.20120205.01

Beyene, Y., Mugo, S., Oikeh, S. O., Juma, C., Olsen, M., \& Prasanna, B. M. (2016). Hybrids performance of doubled haploid lines derived from 10 tropical bi-parental maize populations evaluated in contrasting environments in Kenya. African Journal of Biotechnology, 16(8), 371-379. https://doi.org/10.5897/AJB 2016.15697

CIMMYT. (1985). Managing trials and reporting data for CIMMYT's maize testing program. Mexico, D.F.

Das, B., Atlin, G. N., Olsen, M., Burgueno, J., Tarekegne, A., Babu, R., ... Cairns, J. E. (2019). Identification of donors for low-nitrogen stress with maize lethal necrosis (MLN) tolerance for maize breeding in sub-Saharan Africa. Euphytica, 215, 80. https://doi.org/10.1007/s10681-019-2406-5

Davis, J., Amézquita, M., \& Muñoz, J. (1981). Border Effects and Optimum Plot Sizes for Climbing Beans (Phaseolus vulgaris) and Maize in Association and Monoculture. Experimental Agriculture, 17, $127-35$. https://doi.org/10.1017/S0014479700011364

De Mendiburu, F. (2009). Una herramienta de analisis estadistico para la investigacion agricola (Thesis, Departamento Academio de Estadistica e Informatica, Facultad de Economia y Planificacion, Universidad Nacional La Molina, Lima, Peru).

Dewey, D. R., \& Lu, K. H. (1959). A correlation and path coefficient analysis of components of crested wheat grass and seed production. Agronomy Journal, 51, 515-517. https://doi.org/10.2134/agronj1959.0002196 2005100090002x

Elrod, S., \& Stanfield, W. (2002). Genetics (4th ed.). Tata McGraw Hill Co. New Delhi.

FAOSTAT. (2017). FAOSTAT database. FAO, Rome. Retrieved August 7, 2017, from http://faostat.fao.org

Jahufer, M. Z. Z., \& Luo, D. (2018). "DeltaGen” a comprehensive decision support tool for plant breeders. Crop Science, 58, 1-14. https://doi.org/10.2135/cropsci2017.07.0456

Jakhar, D. S., Singh, R., \& Kumar, A. (2017). Studies on path coefficient analysis in maize (Zea mays L.) for grain yield and its attributes. International Journal of Current Microbiology and Applied Science, 6, 2851-2856. https://doi.org/10.20546/ijcmas.2017.604.327

Jilo, T., Tulu, L., Birhan, T., \& Beksisa, L. (2018). Genetic variability, heritability and genetic advance of maize (Zea mays L.) inbred lines for yield and yield related traits in southwestern Ethiopia. Journal of Plant Breeding and Crop Science, 10, 281-289. https://doi.org/10.5897/JPBCS2018.0742

Johnson, H. W., Robinson, H. F., \& Comstock, R. E. (1955). Estimation of genetic and environmental variability in soybean. Agronomy Journal, 47, 314-318. https://doi.org/10.2134/agronj1955.00021962004700070009x 
Kassie, G. T., Abdulai, A., Greene, W. H., Shiferaw, B., Abate, T., Tarekegne, A., \& Sutcliffe, C. (2017). Modelling preference and willingness to pay for drought tolerance (DT) in Maize in rural Zimbabwe. World Development, 94, 465-477. https://doi.org/10.1016/j.worlddev.2017.02.008

Kumar, S. V. V., \& Babu, D. R. (2015). Character association and path analysis of grain yield and yield components in Maize (Zea mays L.). Journal of Plant Breeding, 6, 550-554.

Kwon, S. H., \& Torrie, J. H. (1964). Heritability and interrelationship among traits of two soybean populations. Crop Science, 4, 196-198. https://doi.org/10.2135/cropsci1964.0011183X000400020023x

Lenka, D. B., \& Mishra, Y. P. (1973). Path coefficient analysis of yield in rice varieties. Indian Journal of Agricultural Science, 43, 376-369.

Makumbi, D., Assanga, S., Diallo, A., Magorokosho, C., Asea, G., Worku, M., \& Banziger, M. (2018). Genetic analysis of tropical Midaltitude-adapted maize populations under stress and non-stress conditions. Crop Science, 58, 1492-1507. https://doi.org/10.2135/cropsci2017.09.0531

Malik, H. N., Malik, S. I., Hussain, M., Chughtai, S. U. R., \& Javed, H. I. (2005). Genetic correlation among various quantitative characters in Maize (Zea mays L.) hybrids. Journal of Agriculture and Social Science, 1 , $262-265$.

Meena, M. K, Singh, R., \& Meena, H. P. (2016). Genetic variability, heritability and genetic advance studies in newly developed maize genotypes (Zea mays L.). The Bioscan, 11, 1787-1791.

Mhike, X., Okori, P., Magorokosho, C., \& Gibson, P. (2012). Genetic analysis of tropical maize inbreds and hybrids for grain yield and traits associated with drought tolerance. Third Rofurom Biennial Meeting, September 24-28, 2012, Entebbe, Uganda.

Musundire, L., Derera, J., Dari, S., \& Tongoona, P. (2019). Genetic variation and path analysis of introgressed maize inbred lines for economic traits. Journal of Agricultural Science, 11, 135-149. https://doi.org/ $10.5539 /$ jas.v11n $17 \mathrm{p} 135$

Ogunniyan, D. J., \& Olakojo, S. A. (2014). Genetic variation, heritability, genetic advance and agronomic character association of yellow elite inbred lines of maize (Zea mays L). Nigerian Journal of Genetics, 28, 24-28. https://doi.org/10.1016/j.nigjg.201506.005

Patterson, H. D., Williams, E. R., \& Hunter, E. A. (1978). Block Designs for Variety Trials. Journal of Agricultural Science (Cambridge), 90, 395-400. https://doi.org/10.1017/S0021859600055507

R Core Team. (2020). R: A language and environment for statistical computing. R Foundation for Statistical Computing Vienna, Austria.

Raghu, B., Suresh, J., Kumar, S. S., \& Saidaish, P. (2011). Character association and path analysis in maize (Zea mays L.). Madras Agricultural Journal, 98, 7-9.

Seshu, G., Jabeen, F., \& Rani, K. J. (2013). Heritability, trait association and path analysis for grain yield and yield contributing characters in maize. The Andhra Agricultural Journal, 60, 563-567.

Shukla, S., Bhargava, A., Chatterjee, A., Sirivastava, J., Singh, N., \& Singh, S. P. (2006). Mineral profile and variability in vegetable amaranth (Amaranthus tricolor). Plant Foods for Human Nutrition, 61, 23-28. https://doi.org/10.1007/s11130-006-0004-X

Singh, R. K., \& Chaudhary, B. D. (1985). Biometrical methods in quantitative analysis (p. 318). Kaylani Publishers, New Delhi.

Siva-Subranamanian, S., \& Menon, M. (1973). Heterosis and inbreeding depression in rice. Madras Agricultural Journal, 60, 1139-1140.

Wright, S. (1921). Correlation and causation. Journal of Agricultural Research, 20, 557-585.

Wuhaib, K. M., Hadi, B. H., \& Hassan, W. A. (2018). Genotypic and phenotypic correlation in maize and path coefficient I-Agronomic traits. Iraqi Journal of Agricultural Sciences, 49, 179-187.

\section{Copyrights}

Copyright for this article is retained by the author(s), with first publication rights granted to the journal.

This is an open-access article distributed under the terms and conditions of the Creative Commons Attribution license (http://creativecommons.org/licenses/by/4.0/). 